\title{
Design thinking in entrepreneurship education: Understanding framing and placements of problems
}

\begin{tabular}{|c|c|}
\hline \multicolumn{2}{|c|}{$\begin{array}{l}\text { Authors: } \\
\text { Thea J. Tselepis }{ }^{1} \\
\text { Carol A. Lavelle }\end{array}$} \\
\hline \multicolumn{2}{|c|}{$\begin{array}{l}\text { Affiliations: } \\
{ }^{1} \text { DHET-NRF South African } \\
\text { Research Chair in } \\
\text { Entrepreneurship Education, } \\
\text { College of Business and } \\
\text { Economics, University of } \\
\text { Johannesburg, Johannesburg, } \\
\text { South Africa }\end{array}$} \\
\hline \multicolumn{2}{|c|}{$\begin{array}{l}{ }^{2} \text { Department of Fashion } \\
\text { Design, Faculty of Art, Design } \\
\text { and Architecture, University } \\
\text { of Johannesburg, } \\
\text { Johannesburg, South Africa }\end{array}$} \\
\hline \multicolumn{2}{|c|}{$\begin{array}{l}\text { Corresponding author: } \\
\text { Thea Tselepis, } \\
\text { theat@uj.ac.za }\end{array}$} \\
\hline \multicolumn{2}{|c|}{$\begin{array}{l}\text { Dates: } \\
\text { Received: } 19 \text { May } 2020 \\
\text { Accepted: } 21 \text { July } 2020 \\
\text { Published: } 22 \text { Sept. } 2020\end{array}$} \\
\hline \multicolumn{2}{|c|}{$\begin{array}{l}\text { How to cite this article: } \\
\text { Tselepis, T.J. \& Lavelle, C.A., } \\
\text { 2020, 'Design thinking in } \\
\text { entrepreneurship education: } \\
\text { Understanding framing and } \\
\text { placements of problems', } \\
\text { Acta Commercii 20(1), a872. } \\
\text { https://doi.org/10.4102/ } \\
\text { ac.v20i1.872 }\end{array}$} \\
\hline \multicolumn{2}{|c|}{$\begin{array}{l}\text { Copyright: } \\
\text { (c) 2020. The Authors. } \\
\text { Licensee: AOSIS. This wo } \\
\text { is licensed under the } \\
\text { Creative Commons } \\
\text { Attribution License. }\end{array}$} \\
\hline \multicolumn{2}{|l|}{ Read online: } \\
\hline 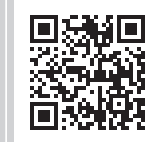 & $\begin{array}{l}\text { Scan this QR } \\
\text { code with your } \\
\text { smart phone or } \\
\text { mobile device } \\
\text { to read online. }\end{array}$ \\
\hline
\end{tabular}

Orientation: Design thinking presented an alternative lens for entrepreneurship education.

Research purpose: The purpose of this article was to illustrate (with a framework) the benefits of encouraging a design-based mindset when exploring problem placement and framing to create new opportunities for entrepreneurship students.

Motivation for the study: The role of placement and framing of open-complex problems has not been fully embraced in the literature on design thinking for entrepreneurship education. The seminal work of Richard Buchannan (a great influencer in the realm of design thinking) offered a deeper insight into the placement and framing of problems that could assist educators to facilitate thinking skills relevant to deal with the unpredictable contexts that future entrepreneurs have to be prepared for.

Research design, approach and method: This conceptual paper adopts a basic qualitative research approach that develops an extension of knowledge within the field of entrepreneurship education for the purpose of informing the development of practice. The principle method used is a progressive consideration of different theoretical perspectives and seminal studies concerning entrepreneurship education and design thinking in order to conceptualise the development of a framework that promotes framing and placements of problems. An interpretive paradigm is applied.

Main findings: The proposed framework offered a synthesis between the placement and framing of open-complex problems and the relevant thinking skills: invention, decision, judgement and evaluation to consider meaningful solution identification. These thinking skills are imperative for future entrepreneurs who need to transform their novel ideas in innovative ways.

Practical/managerial implications: The framework requires a paradigm shift from prediction and goal setting and may empower educators who apply a design thinking approach to entrepreneurship education.

Contribution/value-add: An in-depth understanding of problem placement and framing can assist educators in the field to make informed decisions about their approaches to entrepreneurship education when applying a design thinking methodology.

Keywords: design thinking; entrepreneurship education; open-complex problems; design lens; solving problems.

\section{Introduction}

There has been an increasing interest in scholarly literature that recognises the similarities of entrepreneurship and design as both being a complex, non-linear process. Linton and Klinton (2019), however, express that there remains a tendency for entrepreneurial education to rely on a traditional business approach with a focus on the linearity of planning and prediction. The effectiveness of entrepreneurial education that emphasises the development of a business plan as the main assessment output, without a thorough exploration of the initial idea or opportunity, has been questioned in a number of papers (Daniel 2016; Linton \& Klinton 2019; Neck \& Greene 2011; Piperopoulos 2012). The tendency to approach entrepreneurship education using traditional business approaches may have a negative impact on students' entrepreneurial intentions (Piperopoulos 2012). Nevertheless, Linton and Klinton (2019) argued that the continued use of teaching entrepreneurship that requires linear thinking can probably be linked to two main reasons: (1) investment for business requires prediction and (2) it could be because it is familiar to educators who apply a business administration perspective. 
The purpose of this article is to illustrate that it may be beneficial to encourage a design-based mindset when exploring problem placement and framing to create new opportunities, with implications for entrepreneurial education. An interpretivist paradigm is used in this conceptual article to:

- validate the relevance of a design lens in entrepreneurship education from existing literature to support an understanding of design thinking

- propose a framework that supports an understanding of design problem framing and placement within design thinking

- provide the implications for the proposed framework for entrepreneurship education.

Scholarly work on the relevance of design in entrepreneurship education makes it clear that there is a place for facilitating students to think like designers (Daniel 2016; Neck \& Greene 2011). The discourse on the parallels between entrepreneurship and design revolves mainly around design thinking (Daniel 2016; Neck \& Greene 2011; Nielsen \& Christensen 2014; Nielsen \& Stovang 2015).

Design thinking is often proposed as a framework for thinking and doing in an iterative way to promote convergent and divergent thinking (Dong, Massimo \& Lovallo 2016). The focus when using design thinking as a methodology for strategy that incorporates the thinking, actions, objects and services and arguments that individuals take or have to take in order to enhance a competitive advantage is also useful (Diderich 2020). The process of design thinking is highlighted in the literature on entrepreneurship and we accept the valuable contributions in the literature on the application of design thinking as a method to solve complex problems and acknowledge that it therefore has a place in entrepreneurship education. Nevertheless, dealing with complex problems also links to how well they are placed and framed.

Literature on design thinking in entrepreneurship revolves mainly around the process of innovation and problem framing or if placement is neglected. In this regard, Buchanan $(1992,1998)$ has had a major influence on the discourse of design thinking within other disciplines and his views about placement and framing of problems through design thinking seems lacking in discourses on entrepreneurship. In his seminal work on design thinking, Buchanan (1992) argued that there are four interconnected placement areas where design problems emerge that serve as a framework for human experience. These problem placement areas are concerned with communication (signs, images and symbols), construction (objects), strategy (actions) and systemic integration (thought). We draw on Buchannan's work and argue that it would be beneficial for educators in entrepreneurship, to apply design thinking as a framework for human experience to frame a problem as a starting point for their iterative transformation processes, and hence, we view it as important for entrepreneurship education.

We endorse the view of Neck and Greene (2011), who conceptualised entrepreneurship education as a method within an applied science. In this article, we therefore expand their view and argue that teaching entrepreneurship as a method within an applied science implies that educators could be more focused on exploring the framing and placement of open-complex problems in a curriculum. We illustrate how framing open-complex problems could be more relevant in disruptive and dynamic environments where prediction is almost impossible at times.

This article firstly provides a discussion of design thinking with reference to how it is typically used in entrepreneurship education. Secondly, the article offers our contribution to proposing a synthesis of Buchanan's (1992, 1998) placement theory as a means to frame open-complex problems that may be applied in entrepreneurship education at a tertiary level. The implications for such a framework are provided in the final conclusion of this article.

\section{The role of design thinking in entrepreneurship education}

Curriculum development is an act of design in itself and is usually developed bearing in mind that educators and their advisory committees consider this to be the most important aspect of the programme (Collins 2017). Curriculum design practice also requires that consideration about a discipline should be validated with theory and scholarly methods that align to the envisioned outcomes of the educational programme (Neck \& Greene 2011). The perspective that the educators use to analyse their discipline, however, should be understood to fully embrace the theories that can be linked to it (Conrad 2019). The relevance of viewing entrepreneurship from a design perspective (lens) is therefore considered in the following section.

\section{A design lens for entrepreneurship}

To understand design as a perspective or lens rather than a discipline that offers tools to create or develop ideas or strategies, a discussion of design as a discipline is firstly unpacked.

\section{Design}

Activities of design continually develop within the context of economic, social, technological and global change (Buchanan, Doordan \& Margolin 2010:7). Design can be considered both as a verb and a noun that provides a bridge between theory and practice that can be applied in many different areas. Although there is no singular definition of design, Margolin (2009:37) suggested that design can be broadly considered as 'conception and planning of the artificial world'. These views acknowledge that design is a pluralistic area of study that is interdisciplinary in nature and can be productively incorporated into any area of human activity. Therefore, design can be evident within all aspects of everyday contemporary life at different levels of complexity. 
The complexity of design is highlighted by the opencomplex problems that designers are faced with whereby designers need '...to conceive and plan what does not yet exist ..., before the final result is known' (Buchanan 1992:18). The nature of open-complex problems is that each attempt to solve the problem shifts the understanding of what the problem may be (Buchanan 1992; Nielsen \& Christensen 2014). Designers are required to invent a framework to define the design situation as well as develop explanations of how problems may be solved in any particular circumstance. Solutions can be concrete or more abstract, for example, products (tangible) or strategies (intangible) for a society (Chou 2018).

Val et al. (2017) highlight that design is not always aimed to achieve pre-determined goals. Although it is tempting to try and simplify the activity or process of design, Buchanan (1992) argued that the integrative nature of design draws interest from other disciplines, not because they are looking for common philosophies or methodologies, but rather because of a common interest in conceiving and planning what does not yet exist to enrich human lives in complex environments such as living, working, playing and learning. The versatility of design is therefore apparent.

Scholars and authors who have an interest in design concur that the process of surging between problem definition and problem solution is not a linear process but rather iterative (Buchanan 1992; Cross 2001; Dorst 2011; Johansson-Sköldberg, Woodilla \& Cetinkaya 2013; Lawson 2006; Yu, Yue \& Halling 2018). Authors who apply design methodologies to solve open-complex problems refer to design as being innovative but messy at times, because the parameters change during the process of design and applying novel ways to solve problems are often required (Ney \& Meinel 2019). Design incorporates thinking tools and iterative processes that allow designers (and in many cases their potential users) to reframe problem definition that can be solved in creative ways (Garbuio et al. 2018). Design can therefore be viewed as a discovery process where novelty is found, but is motivated by transformation or change for improvement of a current situation.

Some prominent themes that overlap with entrepreneurship can be identified to understand the relevance of design thinking in entrepreneurship.

\section{The themes of entrepreneurship with a focus on design}

The aim of this section is to identify the most prominent themes that parallel with design with reference to the understanding of entrepreneurship as a discipline. In line with design, definitions for entrepreneurship are diverse and range from having a focus of starting ventures to a more comprehensive view that involves corporateentrepreneurship (Kuratko \& Morris 2018) and social entrepreneurship (Kee 2017). Other authors include entrepreneuring in their view of entrepreneurship as an act of bringing about the new (Antonacopoulou \& Fuller 2019). Another construct that emerged from the field of entrepreneurship is entrepreneurial orientation that involves entrepreneurial behaviour and it is acknowledged to be applicable not only in new venture creation (Covin \& Lumkin 2011; Gupta \& Gupta 2015; Lee et al. 2019; Wales 2016). Some authors prefer to focus on entrepreneurship as the field that deals with venture creation as the primary goal (Dahalan, Jaafar \& Rosdi 2013; Halim et al. 2017). Nevertheless, new venture creation for new or existing markets, innovative value add, 'filling' potential gaps in markets with novel ideas and even growing businesses exponentially have all been incorporated in the field of entrepreneurship (Bocken \& Snihur 2019). There is, therefore, no particular definition for entrepreneurship, and perhaps, the diversity of the fields bears testimony to the relevance of viewing entrepreneurship as an applied science as Daniel (2016) noted. We therefore view entrepreneurship as the applied science that embraces the role of the entrepreneurs (with their thinking and actions) applied to changing or transforming a current situation into a preferred one.

We draw on the seminal work of Schumpeter (1934) on entrepreneurial development that is underpinned by economic development and focuses on the role of an entrepreneur within a system. The Schumpeterian view of an entrepreneur in an economic system. In this regard, Schumpeter (1934) views the entrepreneur as an agent of change. The idea of agent of change transforms their environments through their thought, actions and processes aligns with theories of design and the role of the designer in their societies when solving open-complex problems (Cook 2019). We therefore view entrepreneurship from a design lens as: the study of yielding novel ideas (including concrete and abstract offerings) in novel ways, in order to add value by sustaining, developing and integrating human needs through meaningful change where possible, or adapting them when necessary within broader complex environments and systems.

From the above design perspective of entrepreneurship, we highlight three prominent themes that could be important to understand the educational purposes: (1) change or transformation, (2) novelty and (3) innovation. We acknowledge that there are several links in entrepreneurship and design but offer these three main themes for this article.

The theme of transformation: In entrepreneurship, it is well acknowledged when the entrepreneur is viewed as a change agent (Daniel 2016; Hagedoorn 1996; Schumpeter 1934). Dew et al. (2008) referred to the transformable environments where entrepreneurs perform their logic and action. This implies that the entrepreneur as an agent of change can reshape or transform their environments with their cognition and action. Dew et al. (2008) explained that this transformative ability is linked to an ability to effectuate in situations where there are no clearly specified goals. In this regard, the parallels between designers and entrepreneurs are apparent because designers too are often expected to transform and/ 
or reshape their environments (Buchanan 1992; Buchanan et al. 2010:7; Cross 2001; Dorst 2011; Lawson 2006). During open- or complex-problem definition and solution, there are no specified goals, but rather an in-depth understanding of the problem as it emerges (Buchanan 1992). An in-depth understanding of the problem creates an opportunity for a meaningful transformation.

The theme of novelty: It seems to be prevalent in many views on entrepreneurship, whether it be new markets, new ideas, new products services or systems, or new venture creation (Weinberger et al. 2018). The construct of novelty is often used in economic systems in particular with reference to unpredictability (Witt 2016). Unpredictability is also an underpinning notion of design (Linton \& Klinton 2019). In this regard, Stroe, Parida and Wincent (2018) referred to effectuation in entrepreneurial behaviour as a creative way to make or create value through the application of problem solving even in unpredictable environments. We therefore endorse the notion of novelty as a result of creativity in entrepreneurship as a way to develop new products or methods or new ventures as well as acting creatively within unpredictable environments (Born \& Altink 1996; Kier \& McMullen 2018).

The theme of innovation: It is prominent in an understanding of entrepreneurship if a design lens is applied. Innovation is often defined as an ability to (re)define and perceive in an atypical manner (Val et al. 2017). Innovation can also apply to outcomes such as products, methods, services or even systems (Poutanen, Soliman \& Stahle 2016). Design thinking is often embraced as a tool to cope with complexity and to use as a driver of innovation (Daniel 2016; Dorst 2011; Glen et al. 2015). It is therefore not surprising that many educators have been applying design thinking methods in their classrooms as a way to enhance innovative ideas.

Gong (2020) notes the increasing popularity over the last decade to apply design thinking in entrepreneurship. The relevance of a design lens in entrepreneurship has been discussed in the previous section. The relevance of design thinking in entrepreneurship education will be further discussed in the following section to highlight the scholarly work that has been performed in this area.

\section{The application of design thinking in entrepreneurship education}

Design thinking is defined as a complex thinking process 'of conceiving new realities and expressing the introduction of design culture and its methods into fields such as business and innovation' (Val et al. 2017: 759). Moreover, design thinking is also a method that focuses on human needs and is applied to creative problems solving (Daniel 2016; Neck \& Greene 2011). Design Thinking can enable a person to link inspiration and conceptualisation to solve problems (Micheli et al. 2019). It is important to note that the concept 'design thinking' can be viewed as a combination of thinking and knowing and acting in the world (Kimbell 2011). Design thinking can therefore be perceived as the thinking through doing and doing through thinking.

Design thinking provides a framework to solve real problems in innovative ways (Daniel 2016; Pinheiro \& Stensaker 2014). This framework may be applied iteratively that includes empathy (understand and observe), definition of the perceived problem, ideation of possible solutions, prototyping and testing (Val et al. 2017). Phases of design thinking are applied in iterative ways, which implies that some phases will reoccur several times before a viable problem is solved (Glen et al. 2015). According to Brown (2009), inspiration, ideation and implementation are evident when using a design thinking approach and these phases are often applied in education and training settings.

Entrepreneurship education in particular therefore often applies design thinking for innovative problem solving (Brown 2009; Daniel 2016). In this regard, Neck and Greene (2011:66) highlight that in the complex world of today, it is no longer adequate for entrepreneurial education to adopt quantitative, analytical and deductive approaches when attempting to solve '...illdefined, unstructured, ambiguous, complex, multidisciplinary, holistic, real world problems' and propose a design-based approach to identify unique venture opportunities within the specific contexts. It must therefore be noted that it is important not to attempt to simplify the process of inspiration and ideation before the implementation phase of design thinking and in this way reduce entrepreneurial education to the development of a business plan that requires a fair amount of prediction.

There seems to be compelling arguments for entrepreneurship education to progress from description, prediction, decision to rather embrace action that is supported by design thinking (Neck \& Greene 2011). The first argument encourages a need for entrepreneurial programmes to empower students to be agile and be able to cognitively cope with complexity, but still drive entrepreneurial innovation in dynamic and disruptive environments (Glen et al. 2015). Another argument for teaching entrepreneurship as action-motivated is the notion of entrepreneurship that is often interdisciplinary or multidisciplinary because entrepreneurship is not necessarily rooted in business management fields only (Pinheiro \& Stensaker 2014; Ramsey et al. 2011). In this regard, the need for a university that supports design thinking in a real-world context is noted (Pinheiro \& Stensaker 2014).

Design thinking in entrepreneurship education allows tertiary educators to have students work in groups with other students from other programmes (Linton \& Klinton 2019). Studies on interdisciplinary collaboration have been encouraged as a method to teach entrepreneurship (Daniel 2016). It is important to note that the construction of knowledge during design thinking is the students' knowledge that is constructed with the experiences and insights that come from the inputs of others in a particular 
context (Scheer, Noweski \& Meinel 2012). Educators therefore implement design thinking in their courses because it not only allows their students to apply cognition relevant to entrepreneurship, but it also allows the development of critical crossfield outcomes such as the application of creativity and collaboration to develop insights or ideas that are novel and / or innovative (Pinheiro \& Stensaker 2014).

Relevant scholarly work on teaching paradigms and even theories that support design thinking in entrepreneurship education have also been disseminated.

\section{A teaching paradigm that supports design thinking in entrepreneurship education}

New insights and knowledge creation is associated with social constructivism (Higgins et al. 2015; Jung 2017; Löbler 2006; van Aalst 2009). Design thinking within an educational setting can be underpinned by social constructivism (Scheer et al. 2012; Sheppard 2020). Social constructivism can be defined as the way in which people make meaning from objects as well as from social interaction, but the meaning does not stem from objects directly (Amineh \& Asl 2015; Kim 2001). This approach to teaching and learning implies that students who use design thinking may be able to make meaning or mental connections between aspects of what they know and how to implement or use it. A theory that could support a social constructivism thinking paradigm that might be considered when thinking and doing is used in entrepreneurship education is effectuation.

Effectuation is a theory that deals with the decision-making about cause and effect in situations where transformation or change is required (Brettel et al. 2014). Dew et al. (2008) highlighted that effectuation is an advancement of the early cognitive entrepreneurship that focused on topics such as how entrepreneurs think in terms of proposing a potential competitive advantage. Effectuation is not only a way of thinking, but it also informs behaviour that is particularly relevant in identification of processes, opportunity or new venture creation when less certainty is present (Reymen et al. 2015). It is thus important to note that effectuation is usually applied in situations of uncertainty because effectuation has been identified as an appropriate framework for making judgements or decisions involving opportunity evaluation (McMullen 2015).

Effectuation has been applied in design thinking and Dorst (2011) made a case for applying effectuation as a way of thinking in 'entrepreneuring' because he saw that it is an evolving way to solve open-complex problems. The thought leader on effectuation, Sarasvathy (2001:245), states that 'effectuation processes take a set of means as given and focus on selecting between possible effects that can be created with that set of means'. In this article, we therefore view effectuation as a thinking framework that involves a set of heuristics (mental shortcuts) that enable an individual to do what is possible within uncertain circumstances bearing in mind a specific context.

It is important to note that there is a core challenge to review the basic concepts of formal logic that describe the reasoning patterns used to solve problems in different settings if educators want to use effectuation. These concepts are deduction, induction and abduction and Dorst (2011:523) used them to differentiate between the reasoning patterns required to solve closed, well-structured problems and open-complex problems that designers are often faced with. Dorst (2011) explained that in any given situation, different problem-solving reasoning patterns are adopted according to what is known and unknown within the equation of the what (object) + how (working principle) leads to observable results. When solving well-defined problems, the reasoning pattern of deduction is applied to predict how an existing object (e.g. a business plan) with tested methods will perform in different contexts. Inductive reasoning is a creative process applied when the exiting object (e.g. a business plan) is known as well as the expected result, however, the working principle of how to achieve these results needs to be formulated. The proposed working principles can then be tested via deduction to establish whether the same results will be achieved in different situations (Dorst 2011). These logics are typically used in more traditional approaches to entrepreneurship education.

However, in the case of abduction, Dorst (2011) proposed that in design, observable results in the equation are replaced with meeting aspired values of people. In the context of open-complex problems, only the aspired value is known. The object and working principles do not yet exist. An explanation of how (working principles or method) to fulfil this value as well as the creation of the object, service or system needs to be developed. This lack of 'known' is the challenge that entrepreneurs deal with when they attempt to come up with innovative or inventive solutions to problems.

In the context of effectuation, McMullen (2015), as discussed earlier, highlighted the need for making decisions, judging and the evaluation of opportunities as being an important framework used to navigate through uncertain situations. Within the context of design thinking, Buchanan (1998) highlighted that inventing, judging, deciding and evaluating are the cornerstones of all human design abilities; however, these abilities need placements in order to effective within the discipline of designs that will be discussed in the following section. The role of design thinking as a way of promoting abductive reasoning could support invention, which, in turn, is important for entrepreneurship education.

Nevertheless, in order to invent, judge, decide or evaluate, problem placement and framing is important to enable a real understanding of meaningful solutions to open-complex problems so that action and production can occur. 
The following section is our contribution to the discourse of design thinking within entrepreneurship.

We acknowledge that the debate surrounding the concept of design thinking as it has emerged in different discourses has been viewed with some contention (Nussbaum 2011 and Collopy 2009 cited in Johansson-Sköldberg et al. 2013). We, however, take the position that design and creation of improving desired situations is an inherent quality of human nature and daily activity that remains relevant for continued exploration within different contexts. It is with this in mind that we look back to Buchanan's (1992:8) seminal paper on Wicked Problems which discusses his theory on the doctrine of placements whereby he argued that design should not be reduced to a science of theory. Instead, Buchanan (1992) stated that design should be embraced as:

...[A] discipline that may be shared to some degree by all men and women in their daily lives and is, in turn, mastered by a few people who practice the discipline with distinctive insight and sometimes advance it to new areas of innovative application. (p. 8)

In this article, we do not claim to have distinctive insight into design thinking as the panacea to solve all human problems but rather suggest that a productive means to apply design thinking to new situations is to look back to Buchanan's original intention of identifying places where open-complex problems emerge for further consideration.

These four broad placement areas where problem definition and solution need to be considered in contemporary life are identified by Buchanan (1992:9-10) as follows:

Symbolic and visual communication: The representation of signs, symbols and images as a means to communicate abstract ideas. This area extends to all forms of communication such as television, photography, film, print media and all forms of social media to name a few.

Construction of material objects: It requires the development of skills related to construction in order to convert images and symbols into tangible objects and extends to physical, social, psychological and cultural relationships between products and people.

Strategic planning of activities and organisational services: The incorporation of diverse knowledge and values to reach explicit end results that could include the consideration of market needs, manufacturing processes and identifying future markets before inventing and constructing tangible objects. This area extends to logical decision-making that consider how services and organisational structures can contribute to making human experience more intelligent, meaningful and satisfying.

Systemic integration of complex systems for living, working, playing and learning: It focuses on complex systems and environments within human culture that are needed to address social, political, environmental and economic transition (Buchanan et al. 2010:3). Systemic integration considers lived experiences that are not problems of action but rather reaching new understanding of social purposes in search for expression in appropriate activities and products requiring collaboration and individual initiatives that lead to debate (Buchanan 1998:16). This area extends to a consciousness of idea, thought and value that expresses unity and balance to a functioning whole.

Within the context of design, human abilities of inventing, judging, deciding and evaluating enable thought, action and production in order for design solutions to be effective (Buchanan 1992; 1998). Buchanan (1998) proposed that problem placement concerning systemic integration requires the cognitive abilities of evaluating, deciding, judging and inventing alternative solutions when seeking an understanding of core ideas, values and purpose of culture that inform and transform the environment. Strategic planning, construction and communication support potential successful solutions.

As reflected in Figure 1, a problem definition and solution in any one of these placements or areas will have an impact on all of the other placements or areas where design problems and solutions are required. The middle section common to all four placements in Figure 1 represents the viability of a potentially successful design solution. Moreover, the cognitive thinking skills of inventing, judging, deciding and evaluating are important to assist in an in-depth understanding of each placement.

The framework proposed in Figure 1 has some implications for entrepreneurship education and we offer those in the following section.

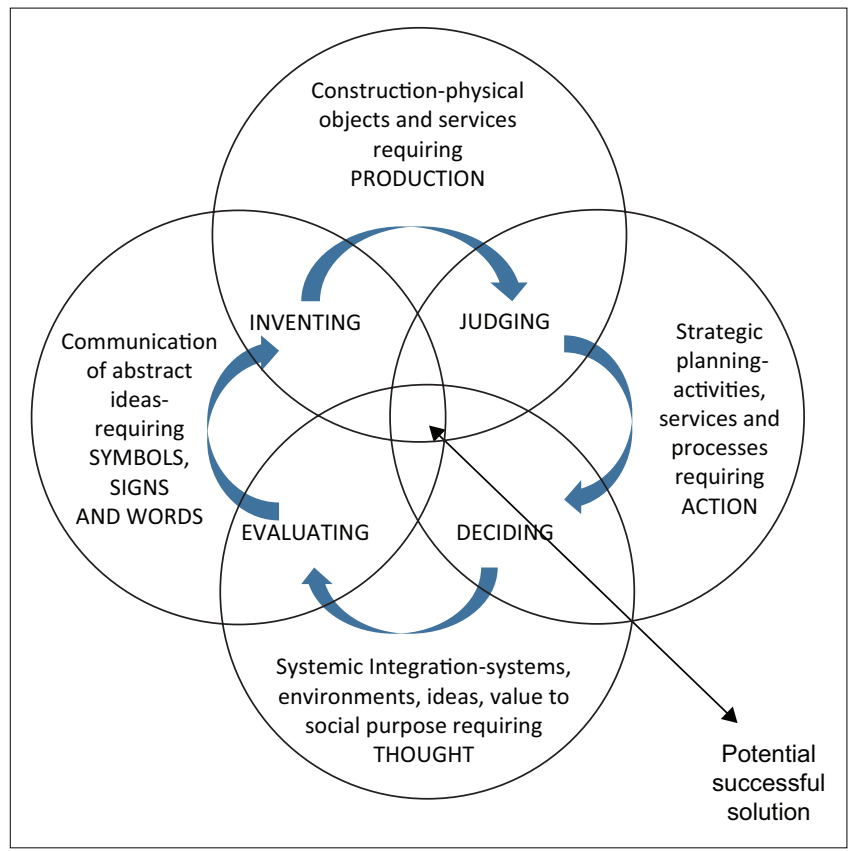

Source: Adaption of Buchanan's (1998) matrix in Buchanan, R., 1998, 'Branzi's dilemma: Design in contemporary culture', Design Issues 14(1), 3-20. https://doi.org/10.2307/1511825 FIGURE 1: Problem placement areas. 


\section{Conclusions and implications}

The design lens for entrepreneurship offers four placement areas where the three themes of transformation, novelty and innovation may be considered by entrepreneurship educators for developing projects for students. Interdisciplinary projects could be used to broaden individual understanding of different views concerning core ideas, values and purpose of culture that inform and transform environments of living, playing, working and learning. Interdisciplinary projects can further be extended to develop strategies that incorporate diverse knowledge to explore novel approaches to providing alternative activities and processes when identifying current and future market needs. Projects concerning the construction of products or services require the development of skills to convert abstract ideas into innovative tangible objects that support physical, social, psychological and cultural relationships between products and people. Projects concerning communication of signs and symbols can be developed to promote the communication of product intention, pitching ideas and creating both novel and innovative ways of interconnectivity, especially within the context of technological development. Projects on strategic planning could include the consideration of market needs, manufacturing processes and identifying future markets before inventing and constructing tangible objects.

Educators' understanding that a problem might move from one placement to another as the solutions are actioned is important. A problem may, for example, start as one of strategy, but the systemic integration at a point in time prevents that potential solution to be implemented, the students then need to be encouraged to move to communication framing and iterate thinking skills such as inventing, judging, deciding and evaluating. The implications for assessment are that educators need to assess the thought processes rather than only the outputs of project. As for business planning, we hope to have persuaded some educators to at least see that the thinking in a traditional business plan is not ideal in preparing final year students to operate (action driven) within uncertainty. Yet, the ability to use abductive reasoning within the uncertainty and deal with the unknown might well be the 'real problem' to solve when we teach entrepreneurship as a method. Entrepreneurs need to have a lived experience before they can be effective in implementing viable opportunities. Therefore, it is important to note that design thinking in entrepreneurship is increasingly relevant in uncertain times.

To end this article, we commend those who apply design thinking as a method in their education of entrepreneurship, but we also dare others to step out of the discipline of business administration and fully embrace the framing and placements of problems when offering entrepreneurship education as a method to enhance dealing with complex problems through the lens of design.

\section{Acknowledgements}

\section{Competing interests}

The authors declare that no competing interest exists.

\section{Authors' contributions}

T.T. and C.L. conceived the presented ideas. T.T. developed the structure and flow and wrote the part on entrepreneurship education. C.L. wrote parts of the seminal theories on design thinking and synthesised those with T.T.'s structure. T.T. did technical editing and C.L. did language editing.

\section{Ethical consideration}

This article followed all ethical standards for research without direct contact with human or animal subjects.

\section{Funding information}

This research received no specific grant from any funding agency in the public, commercial or not-for-profit sector.

\section{Data availability statement}

Data sharing is not applicable to this article as no new data were created or analysed in this study.

\section{Disclaimer}

The views and opinions expressed in this article are those of the authors and do not necessarily reflect the official policy or position of any affiliated agency of the authors.

\section{References}

Amineh, R.J. \& Asl, H.D., 2015, 'Review of constructivism and social constructivism', Journal of Social Sciences, Literature and Languages 1(1), 9-16.

Antonacopoulou, E.P. \& Fuller, T., 2019, 'Entrepreneurship as practice extended: Emplacement in entrepreneuring', Academy of Management Proceedings 2019(1), 10349. https://doi.org/10.5465/AMBPP.2019.10349abstract

Bocken, N. \& Snihur, Y., 2019, 'Lean Startup and the business model: Experimenting for novelty and impact', Long Range Planning 53(3), 101953. https://doi.org/ 10.1016/j.Irp.2019.101953

Born, M.P. \& Altink, W.M., 1996, 'The importance of behavioural and situational characteristics for entrepreneurial success: An international rating study',
International Journal of Selection and Assessment 4(2), 71-77. https://doi.org/ 10.1111/j.1468-2389.1996.tb00061.x

Brettel, M., Bendig, D., Keller, M., Friederichsen, N. \& Rosenberg, M., 2014, 'Effectuation in manufacturing: How entrepreneurial decision-making techniques can be used to deal with uncertainty in manufacturing', Procedia CIRP 17(47) 611-616. https://doi.org/10.1016/j.procir.2014.03.119

Brown, T., 2009, Change by design: How design thinking transforms organisation and inspires innovation, Harper Collins, New York, NY.

Buchanan, R., 1992, 'Wicked problems in design thinking', Design Issues 8(2), 5-21.

Buchanan, R., 1998, 'Branzi's dilemma: Design in contemporary culture', Design Issues 14(1), 3-20. https://doi.org/10.2307/1511825

Buchanan, R., Doordan, D. \& Margolin, V., 2010, 'Introduction', in R. Buchanan, D. Doordan \& V. Margolin (eds.), The designed world: Images, objects, environments, pp. 7-11, Berg, Oxford.

Chou, D.C., 2018, 'Applying design thinking method to social entrepreneurship project', Computer Standards \& Interfaces 55(1), 73-79. https://doi.org/10.1016/j. csi.2017.05.001

Collins, A., 2017, What's worth teaching?: Rethinking curriculum in the age of technology, Teachers College Press, New York, NY.

Cook, T.V.D.M., 2019, 'Design dialogs as a specific mode of communication: About the ongoing exploration of solution space', Design Discourse on Culture and Society: Research 5(5), 121-132. 
Conrad, C.F., 2019, The undergraduate curriculum: A guide to innovation and reform, Routledge, New York, NY.

Covin, J.G. \& Lumpkin, G.T., 2011, 'Entrepreneurial orientation theory and research: Reflections on a needed construct', Entrepreneurship Theory and Practice 35(5), 855-872. https://doi.org/10.1111/j.1540-6520.2011.00482.x

Cross, N., 2001, 'Designerly ways of knowing: Design discipline versus science', Design Issues 17(3), 49-55. https://doi.org/10.1162/074793601750357196

Dahalan, N., Jaafar, M. \& Rosdi, S.A.M., 2013, 'Local community readiness in entrepreneurship: Do gender differ in searching business opportunity', Procedia Social and Behavioral Sciences 91(1), 403-410. https://doi.org/10.1016/j. sbspro.2013.08.437

Daniel, A.D., 2016, 'Fostering an entrepreneurial mindset by using a design thinking approach in entrepreneurship education', Industry and Higher Education 30(3), approach in entrepreneurship education', Industry and

Dew, N., Read, S., Sarasvathy, S.D. \& Wiltbank, R., 2008, 'Outlines of a behavioral theory of the entrepreneurial firm', Journal of Economic Behavior \& Organization 66(1), 37-59. https://doi.org/10.1016/j.jebo.2006.10.008

Diderich, C., 2020, Design thinking for strategy, Springer, Richterswil.

Dong, A., Massimo G. \& Lovallo, D., 2016, 'Generative sensing in design evaluation', Design Studies 45(Part A), 68-80. https://doi.org/10.1016/j.destud.2016.01.003

Dorst, K., 2011, 'The core of design thinking and its application', Design Studies 32(6), 521-532. https://doi.org/10.1016/j.destud.2011.07.006

Garbuio, M., Dong, A., Lin, N., Tschang, T. \& Lovallo, D., 2018, 'Demystifying the genius of entrepreneurship: How design cognition can help create the next generation of entrepreneurs', Academy of Management Learning \& Education 17(1), 41-61. https://doi.org/10.5465/amle.2016.0040

Glen, R., Suciu, C., Baughn, C.C. \& Anson, R., 2015, 'Teaching design thinking in business schools', The International Journal of Management Education 13(2), 182-192. https://doi.org/10.1016/j.ijme.2015.05.001

Gong, C., 2020, 'Design thinking transforms teaching approaches and curriculum development for entrepreneurship education', in International conference on modern educational technology and innovation and entrepreneurship (ICMETIE 2020), Atlantis Press, January 11-12, 2020, pp. 162-165.

Gupta, V. \& Gupta, A., 2015, 'The concept of entrepreneurial orientation', Foundations and TrendsinEntrepreneurship11(2),55-137.https://doi.org/10.1561/0300000054

Hagedoorn, J., 1996, 'Innovation and entrepreneurship: Schumpeter revisited', Industrial and Corporate Change 5(3), 883-896. https://doi.org/10.1093/icc/5.3.883

Halim, H.A., Ahmad, N.H., Ramayah, T. \& Hanifah, H.M., 2017, 'Entrepreneurial readiness towards venture creation among bop community', International Journal of Entrepreneurship 21(2), 1-12.

Higgins, D., Trehan, K., McGowan, P., Refai, D., Klapper, R.G. \&Thompson, J., 2015 'A holistic social constructionist perspective to enterprise education', International Journal of Entrepreneurial Behavior \& Research 21(3), 316-337. https://doi. org/10.1108/IJEBR-01-2014-0006

Johansson-Sköldberg, U., Woodilla, J. \& Çetinkaya, M., 2013, 'Design thinking: Past, present and possible futures', Creativity and Innovation Management 22(2), 121-146. https://doi.org/10.1111/caim.12023

Jung, H., 2017, 'Knowledge creation without deliberate knowledge management: A case study in an innovative firm', Doctoral dissertation, University of Gloucestershire.

Kee, D.M., 2017, 'Defining social entrepreneurship: A Schumpeterian non-solution', International Journal of Entrepreneurship and Small Business 31(3), 416-433. https://doi.org/10.1504/IJESB.2017.084843

Kier, A.S. \& McMullen, J.S., 2018, 'Entrepreneurial imaginativeness in new venture ideation', Academy of Management Journal 61(6), 2265-2295. https://doi. org/10.5465/amj.2017.0395

Kim, B., 2001, 'Social constructivism', Emerging Perspectives on Learning, Teaching, and Technology 1(1), 16-27.

Kimbell, L., 2011, 'Rethinking design thinking', Design and culture 3(3), 285-306.

Kuratko, D.F. \& Morris, M.H., 2018, 'Corporate entrepreneurship: A critical challenge for educators and researchers', Entrepreneurship Education and Pedagogy 1(1), 42-60. https://doi.org/10.1177/2515127417737291

Lawson, B., 2006, How designers think: The design process demystified, 4th edn. Architectural Press, Oxford.

Lee, Y., Zhuang, Y., Joo, M. \& Bae, T.J., 2019, 'Revisiting Covin and Slevin (1989) Replication and extension of the relationship between entrepreneurial orientation and firm performance', Journal of Business Venturing Insights 12(1), 00144 https://doi.org/10.1016/j.jbvi.2019.e00144

Linton, G. \& Klinton, M., 2019, 'University entrepreneurship education: A design thinking approach to learning', Journal of Innovation and Entrepreneurship 8(1), 1-11. https://doi.org/10.1186/s13731-018-0098-z

Löbler, H., 2006, 'Learning entrepreneurship from a constructivist perspective', Technology Analysis \& Strategic Management 18(1), 19-38. https://doi. org/10.1080/09537320500520460
Margolin, V., 2009, 'Design history and design studies', in H. Clark \& D Brody (eds.), Design studies a reader, pp. 34-41, Berg, Oxford.

McMullen, J.S., 2015, 'Entrepreneurial judgment as empathic accuracy: A sequential decision-making approach to entrepreneurial action', Journal of 413000386

Micheli, P., Wilner, S.J., Bhatti, S.H., Mura, M. \& Beverland, M.B., 2019, 'Doing design thinking: Conceptual review, synthesis, and research agenda', Journal of Product Innovation Management 36(2), 124-148. https://doi.org/10.1111/jpim.12466

Neck, H.M. \& Greene, P.G., 2011, 'Entrepreneurship education: Known worlds and new frontiers', Journal of Small Business Management 49(1), 55-70. https://doi. org/10.1111/j.1540-627X.2010.00314.x

Ney, S. \& Meinel, C. (eds.), 2019, 'Leadership, design thinking and messy institutions', in Putting design thinking to work, pp. 47-167, Springer, Cham.

Nielsen, S.L. \& Christensen, P.R., 2014, 'The wicked problem of design management: Perspectives from the field of entrepreneurship', The Design Journal 17(4), 560-582. https://doi.org/10.2752/175630614X14056185480113

Nielsen, S.L. \& Stovang, P., 2015, 'DesUni: University entrepreneurship education through design thinking', Education+ Training 57(8/9), 977-991. https://doi. through design thinking,
org/10.1108/ET-09-2014-0121

Pinheiro, R. \& Stensaker, B., 2014, 'Designing the entrepreneurial university: The interpretation of a global idea', Public Organization Review 14(4), 497-516. https://doi.org/10.1007/s11115-013-0241-z

Piperopoulos, P., 2012, 'Could higher education programmes, culture and structure stifle the entrepreneurial intentions of students?', Journal of Small Business and Enterprise Development 19(3), 461-483. https://doi.org/10.1108/ 14626001211250162

Poutanen, P., Soliman, W. \& Ståhle, P., 2016, 'The complexity of innovation: An assessment and review of the complexity perspective', European Journal of Innovation Management 15(2), 182-207. https://doi.org/10.1108/EJIM-03-20140036

Ramsey, E., Smith, K., Martin, L. \& Gibb, A., 2011, 'Concepts into practice: Meeting the challenge of development of entrepreneurship educators around an innovative paradigm', International Journal of Entrepreneurial Behavior \& Research 17(2) 146-165. https://doi.org/10.1108/13552551111114914

Reymen, I.M., Andries, P., Berends, H., Mauer, R., Stephan, U. \& Van Burg, E., 2015 'Understanding dynamics of strategic decision making in venture creation: A process study of effectuation and causation', Strategic Entrepreneurship Journa 9(4), 351-379. https://doi.org/10.1002/sej.1201

Sarasvathy, S.D., 2001, 'Causation and effectuation: Toward a theoretical shift from economic inevitability to entrepreneurial contingency', Academy of Management Review 26(2), 243-263. https://doi.org/10.5465/AMR.2001.4378020

Scheer, A., Noweski, C. \& Meinel, C., 2012, 'Transforming constructivist learning into action: Design thinking in education', Design and Technology Education: An International Journal 17(3), 201-217.

Schumpeter, J.A., 1934, The theory of economic development, Oxford University Press, London.

Sheppard, M.J., 2020, 'A case study of a radical constructivist approach to teaching innovation', Journal of Education for Business, 1-8. https://doi.org/10.1080/0883 2323.2020.1715331

Stroe, S., Parida, V. \& Wincent, J., 2018, 'Effectuation or causation: An fsQCA analysis of entrepreneurial passion, risk perception, and self-efficacy', Journal of Business Research 89(1), 265-272. https://doi.org/10.1016/j.jbusres.2018.01.035

Val, E., Gonzalez, I., Iriarte, I., Beitia, A., Lasa, G. \& Elkoro, M., 2017, 'A design thinking approach to introduce entrepreneurship education in European school curricula' The Design Journal 20 (suppl. 1), S754-S766. https://doi.org/10.1080/14606925. 2017.1353022

Van Aalst, J., 2009, 'Distinguishing knowledge-sharing, knowledge-construction, and knowledge-creation discourses', International Journal of Computer-Supported Collaborative Learning 4(3), 259-287. https://doi.org/10.1007/s11412-0099069-5

Wales, W.J., 2016, 'Entrepreneurial orientation: A review and synthesis of promising research directions', International Small Business Journal 34(1), 3-15. https://doi. org/10.1177/0266242615613840

Weinberger, E., Wach, D., Stephan, U. \& Wegge, J., 2018, 'Having a creative day: Understanding entrepreneurs' daily idea generation through a recovery lens', Journal of Business Venturing 33(1), 1-19. https://doi.org/10.1016/j. jbusvent.2017.09.001

Witt, U. (ed.), 2016, 'Novelty and the bounds of unknowledge in economics', in Rethinking economic evolution, pp. 115-130, Edward Elgar Publishing, New York, NY.

Yu, H., Yue, H. \& Halling, P., 2018, 'Comprehensive experimental design for chemical engineering processes: A two-layer iterative design approach', Chemical engineering processes: A two-layer iterative design approach', Chemical
Engineering Science 189(1), 135-153. https://doi.org/10.1016/j.ces.2018. Enginee
05.047 